\title{
PLAG1 gene alterations in salivary gland pleomorphic adenoma and carcinoma ex-pleomorphic adenoma: a combined study using chromosome banding, in situ hybridization and immunocytochemistry
}

\author{
Carmo Martins ${ }^{1}$, Isabel Fonseca ${ }^{2}$, Lúcia Roque ${ }^{1}$, Teresa Pereira ${ }^{2}$, Catarina Ribeiro ${ }^{1}$, \\ Jörn Bullerdiek ${ }^{3}$ and Jorge Soares ${ }^{2}$ \\ ${ }^{1}$ Centro de Investigação de Patobiologia Molecular (CIPM), Instituto Português de Oncologia de Francisco \\ Gentil, Lisboa, Portugal; ${ }^{2}$ Serviço de Patologia Morfológica, Instituto Português de Oncologia de Francisco \\ Gentil, Lisboa, Portugal and ${ }^{3}$ Center for Human Genetics, University of Bremen, Bremen, Germany
}

\begin{abstract}
Pleomorphic adenoma is the most common benign tumor of the salivary glands. It has marked histological diversity with epithelial, myoepithelial and mesenchymal-type cells arranged in a variety of architectural and differentiation patterns. Pleomorphic adenoma gene 1 (PLAG1), shown to be consistently rearranged in pleomorphic adenomas, is activated by chromosomal translocations involving $8 \mathrm{q} 12$, the chromosome region that is most frequently affected in these tumors. In this study, we evaluated PLAG1 involvement in salivary gland tumorigenesis by determining the frequency of its alterations in a selected group of 20 salivary gland tumors: 16 pleomorphic adenomas and four carcinomas ex-pleomorphic adenoma, having in common the presence of karyotypic chromosome 8 deviations, either structural, with 8q12 rearrangements, or numerical, with gain of chromosome 8. PLAG1 status was analyzed using in situ hybridization techniques, on metaphase cells, by fluorescence detection and/or interphase cells in paraffin sections, by chromogenic detection. Except for one pleomorphic adenoma case (5\%) that lacked PLAG1 involvement, 17 tumors (85\%), (14 pleomorphic adenomas and three carcinomas ex-pleomorphic adenoma) showed intragenic rearrangements of PLAG1 and the remaining two cases (10\%), (one pleomorphic adenoma and one carcinoma ex-pleomorphic adenoma), had chromosome trisomy 8 only. To further investigate the role of PLAG1 on pleomorphic adenomas tumorigenesis, as well as the putative morphogenesis mechanism, we attempted to identify the cell types (epithelial vs myoepithelial) carrying 8q12/PLAG1 abnormalities by a combined phenotypic/genotypic analysis in four cases (three pleomorphic adenoma and one carcinoma ex-pleomorphic adenoma) characterized by 8q12 translocations and PLAG1 rearrangement. In these cases, both cells populations carried PLAG1 rearrangements. This finding further supports the pluripotent single-cell theory, which postulates that the tumor-initiated, modified myoepithelial cell, evolves into the varied somatic cell phenotypes present in pleomorphic adenoma, and reinforces the role of PLAG1 on the tumorigenesis of benign and malignant pleomorphic adenoma. Modern Pathology (2005) 18, 1048-1055. doi:10.1038/modpathol.3800386; published online 6 May 2005
\end{abstract}

Keywords: PLAG1 gene; cytogenetics; in situ hybridization; pleomorphic adenoma; salivary gland tumors

Pleomorphic adenoma, the most common salivary gland tumor type, shows a marked histological diversity which reflects the epithelial and mesenchymal cell differentiation in its composition. ${ }^{1,2}$

Correspondence: Dr C Martins, PhD, CIPM-Cytogenetic Laboratory, Portuguese Cancer Institute, R. Prof Lima Basto, Lisboa, Portugal.

E-mail: mcmartins@ipolisboa.min-saude.pt

Received 16 November 2004; revised and accepted 21 December 2004; published online 6 May 2005
Extensive cytogenetic studies have revealed that these tumors have highly specific chromosome abnormalities namely 3p21, 8q12 and 12q13-15 rearrangements and trisomy $8 .^{3-6}$

Among them, 8q12 deviations constitute the largest cytogenetic subgroup, the most frequent structural aberration being the reciprocal translocation $\mathrm{t}(3 ; 8)(\mathrm{p} 21 ; \mathrm{q} 12)$. Molecular characterization of the $\mathrm{t}(3 ; 8)$ translocation allowed the identification of two genes, PLAG1 and CTNNB1 involved at $8 \mathrm{q} 12$ and $3 \mathrm{p} 21$, respectively. ${ }^{7}$ The former is a 
developmentally regulated zinc-finger gene, activated by a promoter swapping mechanism, in which the PLAG1 promoter is replaced by the CTNNB1 gene promoter. ${ }^{7}$ Recently, it was demonstrated that $P L A G 1$ gene acts as a genuine proto-oncogene ${ }^{8}$ and that its overexpression, with deregulation of PLAG1 target genes, is a crucial oncogenic event in pleomorphic adenomas. ${ }^{9}$ Rearrangements of PLAG1 and tissue overexpression were also reported in a large percentage of pleomorphic adenomas showing other molecular 8q12 rearrangement and even in cases without cytogenetically detectable 8q12 aberrations. ${ }^{7,10-12}$

The role of PLAG1 in salivary gland tumors is almost confined to pleomorphic adenomas as well as to carcinomas ex-pleomorphic adenomas arising in them. ${ }^{10,13,14}$

We investigated the status of PLAG1 gene on a selected group of 20 salivary gland tumors comprising 16 pleomorphic adenomas and four carcinomas ex-pleomorphic adenoma, which share karyotypic chromosome 8 deviations, either as structural (8q12 rearrangements) or numerical gains. This study was performed using different in situ hybridization techniques: in metaphase cells, the fluorescence detection (FISH), and/or in interphase cells from formalin-fixed, paraffin-embedded tumor sections, the chromogenic detection (CISH). CISH analysis was aimed at verifying intragenic rearrangements of PLAG1 in uncultured tumor cells, in situ, and at comparing the results obtained with both in situ hybridization approaches.

The histogenesis of pleomorphic adenoma remains a controversial issue, two main theories emerging, the one that explains pleomorphic adenoma as the result of clonal expansion of a single pluripotent cell, ${ }^{15,16}$ and the other which considers that pleomorphic adenoma and other types of biphasic salivary tumors arise from the coordinated growth of cell populations derived from cells with maintained proliferating capability in salivary tissue. ${ }^{17}$ Clonality has been previously demonstrated in pleomorphic adenoma, ${ }^{18-20}$ the studies supporting the view favoring the common pluripotent cell theory for the salivary gland neoplasm. DebiecRychter et $a 1^{18}$ using PLAG1 genetics and immunohistochemistry demonstrated that the gene lesions were present in all tumor cell populations of pleomorphic adenoma, though more distinctly expressed in cells showing mesenchymal phenotype. They postulated that neoplastic cells with a clearly demonstrable epithelial phenotype probably evolve from cells with mesenchymal characteristics. ${ }^{18}$

Aiming at clarifying this issue, and to further elucidating the role of PLAG1 in pleomorphic adenoma morphogenesis, we searched, by a combined genotypic and phenotypic analysis, whether the (cyto)genetic aberrations were expressed by the epithelial cells, the myoepithelial cells or both, using a combination of immunocytochemistry and in situ hybridization techniques, applied to the study of three cases of pleomorphic adenomas and one carcinoma ex-pleomorphic adenoma, all of them presenting a $8 \mathrm{q} 12$ translocation.

\section{Materials and methods}

\section{Case Selection}

In all, 20 previously karyotyped cases of salivary gland pleomorphic adenoma were selected: 16 benign tumors and four with associated carcinoma areas. All of them had in common chromosome 8 deviations, either as structural rearrangements affecting $8 q 12$ region ( $90 \%$ of the cases), or as numerical gain of chromosome 8 (10\% of the cases). One of the benign neoplasms (case 1) had morphologic features fitting with the diagnosis of myoepithelioma. The clinical, histopathological and karyotypic information are provided in Table 1.

\section{Conventional Cytogenetic Analysis}

Chromosome metaphases of tumor cells were obtained from short-term primary cultures as previously described. ${ }^{21}$ Chromosomes were GTGbanded, and the karyotypes were established according to the ISCN rules. ${ }^{22}$ Detailed description of the tumor karyotypes can be retrieved from Table 1.

\section{In Situ Hybridization-FISH and CISH Analysis}

\section{FISH analysis}

FISH analysis was performed on metaphase chromosomes using a set of three PAC clones covering the region of PLAG1 gene. PAC clones DNAs were isolated as described by Rogalla et $a l^{23}$ and labelled, simultaneously, with biotin by random octamer priming, using the Bioprime DNA labelling system (Life Technologies Inc.). A standard FISH protocol was applied. ${ }^{24}$ Biotinylated PLAG1 probe was detected by Cy3-avidin (Jacksons Lab) and chromosomes were counterstained with DAPI-Vectashield mounting solution (Vector). Fluorescence hybridization signals were analyzed and recorded using a Cytovision System (Applied Imaging).

\section{CISH analysis}

CISH was performed on $4 \mu \mathrm{m}$ formalin-fixed paraffin-embedded tissue sections, containing both the normal salivary gland tissue and the neoplastic tissue. Two probes were used: the PLAG1 probe and a (peri)centromeric probe for chromosome 8 (cen8) (ATCC). The centromeric 8 probe was used both to confirm trisomy of chromosome 8 and as a control probe.

CISH analysis was performed as previously described by Alers et al. ${ }^{25} \mathrm{CISH}$ probes were labelled with fluorescein (Amersham Pharmacia), by random priming, as described above. Probe detection was 
Table 1 Clinical, histopathological and karyotypic data from 20 salivary gland tumors with chromosome 8 deviations

\begin{tabular}{|c|c|c|c|c|}
\hline \multicolumn{2}{|c|}{ CaseClassification } & \multirow{2}{*}{$\begin{array}{l}\text { Age/sex } \\
57 / \mathrm{F}\end{array}$} & \multirow{2}{*}{$\begin{array}{l}\text { Location } \\
\text { Parotid }\end{array}$} & \multirow{2}{*}{$\begin{array}{l}\text { Karyotype } \\
45-46, \mathrm{XX}, \mathrm{t}(2 ; 8)(\mathrm{p} 23 ; \mathrm{qq} 22), \mathrm{t}(8 ; 12)(\mathrm{q} 12 ; \mathrm{p} 13)[\mathrm{cp} 8] / 46, \mathrm{XX}[3]\end{array}$} \\
\hline 1 & Pleomorphic adenoma & & & \\
\hline 2 & Pleomorphic adenoma & $45 / \mathrm{M}$ & Parotid & $46, X Y, t(8 ; 9)(q 12 ; p 22-23)[7]$ \\
\hline 3 & Pleomorphic adenoma & $68 / \mathrm{F}$ & Palate & $46, X X, t(5 ; 8)(p 13 ; q 12-13)[8]$ \\
\hline 4 & Pleomorphic adenoma & $51 / \mathrm{M}$ & Parotid & $46, X Y, t(8 ; 10)(q 12 ; q 22)[13]$ \\
\hline 5 & Pleomorphic adenoma & $78 / \mathrm{M}$ & Parotid & $\begin{array}{l}46, \mathrm{XY}, \mathrm{t}(3 ; 8)(\mathrm{p} 21 ; \mathrm{q} 12)[11] / 45, \mathrm{XY}, \mathrm{t}(3 ; 8)(\mathrm{p} 21 ; \mathrm{q} 12), \operatorname{der}(13 ; 15)(\mathrm{q} 10 ; \mathrm{q} 10)[2] / \\
46, \mathrm{XY}[2]\end{array}$ \\
\hline 6 & Pleomorphic adenoma & $37 / \mathrm{F}$ & Submandibular & $46, X X, t(8 ; 15)(q 12 ; q 26)[13]$ \\
\hline 7 & Pleomorphic adenoma & $22 / \mathrm{F}$ & Parotid & 46,X,t(X;2)(q26;q21),t(3;8;9)(p21;q12;p21)[9] \\
\hline 8 & Pleomorphic adenoma & $86 / \mathrm{F}$ & Submandibular & $46, X X, t(3 ; 8)(p 21 ; q 12)[16]$ \\
\hline 9 & Pleomorphic adenoma & $72 / \mathrm{F}$ & Palate & $46, \mathrm{XX}, \mathrm{t}(3 ; 8)(\mathrm{p} 21 ; \mathrm{q} 12)[6]$ \\
\hline 10 & Pleomorphic adenoma & $24 / \mathrm{F}$ & Parotid & $46, \mathrm{XX}, \mathrm{t}(3 ; 8)(\mathrm{p} 21 ; \mathrm{q} 12)[7] / 46, \mathrm{XX}[11]$ \\
\hline 11 & Pleomorphic adenoma & $73 / \mathrm{F}$ & Parotid & $46, \mathrm{XX}, \mathrm{t}(3 ; 8)(\mathrm{p} 21 ; \mathrm{q} 12)[8]$ \\
\hline 12 & Pleomorphic adenoma & $40 / \mathrm{F}$ & Parotid & $46, X X, t(8 ; 9)(q 12 ; p 22-23)[8]$ \\
\hline 13 & Pleomorphic adenoma & $34 / \mathrm{M}$ & Parotid & $45 \sim 46, \mathrm{XY}, \mathrm{t}(3 ; 8)(\mathrm{p} 21 ; \mathrm{q} 12)[\mathrm{cp} 11]$ \\
\hline 14 & Pleomorphic adenoma & $68 / \mathrm{F}$ & Parotid & $44 \sim 46, \mathrm{XX}, \mathrm{t}(3 ; 8)(\mathrm{p} 21 ; \mathrm{q} 12)[\mathrm{cp} 6]$ \\
\hline 15 & Pleomorphic adenoma & $56 / \mathrm{F}$ & Parotid & $47, \mathrm{XX},+8[11] / 46, \mathrm{XX}[15]$ \\
\hline 16 & Pleomorphic adenoma & $33 / \mathrm{F}$ & Parotid & $46, \mathrm{XX}, \mathrm{t}(5 ; 8)(\mathrm{p} 15 ; \mathrm{q} 12)[6] / 46, \mathrm{XX}[10]$ \\
\hline 17 & $\begin{array}{l}\text { Carcinoma ex-pleomorphic } \\
\text { adenoma }\end{array}$ & $48 / \mathrm{M}$ & Parotid & $46, \mathrm{XY}, \mathrm{t}(3 ; 8)(\mathrm{p} 21 ; \mathrm{q} 12)[10]$ \\
\hline $18^{\mathrm{a}}$ & $\begin{array}{l}\text { Carcinoma ex-pleomorphic } \\
\text { adenoma }\end{array}$ & $71 / \mathrm{F}$ & Submandibular & $\begin{array}{l}\text { 105-111,XXXXX,-1,i(1)(q10),del(2)(q13),+3,der(3)t(3;8)(p21;q12) } \times 4, \\
+6,+7,+7,+7, \operatorname{der}(8) \mathrm{i}(8)(\mathrm{q} 10) \mathrm{t}(3 ; 8)(\mathrm{p} 23 ; \mathrm{q} 12) \mathrm{x} 2,+\operatorname{der}(? 9) \mathrm{t}(1 ; 9)(\mathrm{p} 22 ; ?) \times 2, \\
-10,-11,-11, \operatorname{der}(11) \mathrm{t}(11 ; 11)(\mathrm{p} 15 ; \mathrm{q} 13) \times 3, \operatorname{del}(12)(\mathrm{p} 12),-13,-14,-15, \\
-16, \operatorname{del}(16)(\mathrm{q} 22) \times 2,17,-18,-18,-18, \mathrm{i}(18)(\mathrm{q} 10),+19,-21,+22[\mathrm{cp} 8] / \\
46, \mathrm{XX}[3]\end{array}$ \\
\hline 19 & $\begin{array}{l}\text { Carcinoma ex-pleomorphic } \\
\text { adenoma }\end{array}$ & $58 / \mathrm{M}$ & Parotid & $47, \mathrm{XY},+8[10] / 45, \mathrm{X},-\mathrm{Y}[6] / 46, \mathrm{XY}[6]$ \\
\hline 20 & $\begin{array}{l}\text { Carcinoma ex-pleomorphic } \\
\text { adenoma }\end{array}$ & $60 / \mathrm{F}$ & Parotid & 46,XX,ins(3;8)(p21;q12qter)[10] \\
\hline
\end{tabular}

${ }^{\mathrm{a}}$ Case previously published (Jin et $a l^{13}$ ).

performed using horseradish peroxidase antifluorescein (Roche) and $\mathrm{H}_{2} \mathrm{O}_{2}$-diaminobenzidine. Tissue sections were counterstained with hematoxylin and mounted with Entellan (Merck).

In each case, per tissue section, both probes (cen8 and PLAG1) were evaluated in tumor and normal tissue areas. For PLAG1 probe, the number of cells that were analyzed varied between 69 and 237 $($ mean $=197)$ in tumor areas (15 cases) and between 65 and 218 (mean =174) in normal areas (12 cases). Cen8 probe was evaluated in tumor areas (16 cases), the range being $183-218$, $($ mean $=209)$ and in normal areas (16 cases) from 115 to 221 (mean $=195$ ). The number of spots per nucleus was scored as 1, 2, 3, 4 or $>4$ in all cases, excepting one case of carcinoma ex-pleomorphic adenoma, which was aneuploid and in which the range used was 1 to $\geq 10$.

In normal areas, in the assessment of cen 8 probe the mean percentage of nuclei (mean \pm s.d.), containing 1,2 and 3 hybridization signals per nucleus, was, respectively, $30.5 \pm 15.6,68.7 \pm 15.3$ and $0.7 \pm$ 1.1. Similarly the following values: $28.0 \pm 32.8$, $70.4 \pm 28.7$ and $1.7 \pm 1.1$ signals, respectively, were found for PLAG1 probe.

Significant abnormal losses (monosomy) or gains (polisomy) evaluated with the centromeric probe used were considered to be present when the percentage of samples with one or $\geq 3$ signals per nucleus was higher than the mean \pm 3 s.d. of the controls. ${ }^{26}$ We adopted the conservative criteria proposed by Jenkins et $a l^{27}$ in paraffin-embedded tissue sections, assuming that $\geq 10 \%$ of the nuclei with three signals for cen8 and PLAG1 probes, respectively, as trisomy 8 or split of the PLAG1 gene.

\section{Combined Immunocytochemistry and In Situ Hybridization Analysis}

To investigate which tumor differentiated cell type carried the specific cytogenetic lesions, a combined approach of phenotypic and genotypic analysis was performed on paraffin tissue tumor sections, using, respectively, immunocytochemical and FISH techniques. The phenotype of tumor cell populations was established using mouse monoclonal antibodies against calponin (dilution 1:600) (Dako) and cytokeratin CK8-18 (dilution 1:10) (Novocastra) as markers of myoepithelial and epithelial cells, respectively. The slides were incubated for $30 \mathrm{~min}$ at room temperature with the primary antibodies, after antigen retrieval using pressure cooking for $1 \mathrm{~min}$ in citrate buffer $(\mathrm{pH}=6.0)$. The reaction was developed with Cy3-avidin (Jacksons Lab).

Subsequently, FISH was performed, on the same slides, using the PLAG1 probe and the centromeric 8 probe as an internal control. The PLAG1 probe was labelled with digoxigenin and centromeric 8 probe with biotin and detected, respectively, by antidigoxigenin-FITC (Roche) and Cy3-avidin. The nuclei were counterstained with DAPI. Immunocytochemistry and FISH results were analyzed at the same time and recorded using the Cytovision System. 


\section{Results}

\section{Evaluation of PLAG1 Gene Alterations by In Situ Hybridization (FISH and CISH Analysis)}

PLAG1 gene evaluation was feasible in all tumors by metaphase FISH (18 cases) and/or paraffin-section interphase CISH (16 cases) using the PLAG1 probe and the (peri)centromeric probe for chromosome 8 (Table 2).

Intragenic rearrangement of PLAG1 was observed in nine pleomorphic adenoma and three carcinoma ex-pleomorphic adenoma cases by FISH analysis, recognized by hybridization signals of PLAG1 probe on rearranged chromosomes 8 and their translocation partners (split signal). No split signal was detected in cases 10, 11 and 12. Cases 10 and 11, which carried a typical $\mathrm{t}(3 ; 8)(\mathrm{p} 21 ; \mathrm{q} 12)$ did not show the expected rearrangement of PLAG1 gene. Only two signals were observed: one at $\operatorname{der}(8)$ and one at the normal chromosome 8. There was no signal at the translocation partner der(3). The signal on $\operatorname{der}(8)$ appeared smaller than the signal on normal chromosome 8, indicating that a deletion of $3 p$ sequences along with the $t(3 ; 8)$ had presumably occurred. In the two cases showing trisomy 8 (cases 15 and 19), three copies of PLAG1 were detected without PLAG1 region rearrangement. In cases 1 and 9, it was not possible to assess PLAG1 status due to lack of metaphases.

By CISH analysis, PLAG1 could be evaluated in 15 cases, confirming split of PLAG1 in a significant number of nuclei, which displayed three signals on FISH-positive cases and evidenced PLAG1 rearrangements on unprobed PLAG1 cases $1(20.1 \%)$ and 9 (29.5\%) (Table 2). Except for case 19, that showed $21.6 \%$ of nuclei with three signals/copies confirm- ing trisomy 8 , all the other cases probed with the centromeric 8 probe were disomic.

In cases 10 and 11, which were 'split PLAG1 negative by FISH', the three signal counts per nucleus were, respectively, 9.7 and $14.0 \%$ of the nuclei analyzed. These values fulfilled the adopted criteria of $\geq 10 \%$ for PLAG1 split, comprehensively on case 11 and at the lower limit for case 10 . These two cases were interpreted as positive for PLAG1 rearrangement. CISH confirmed the absence of intragenic rearrangement of PLAG1 in case 12, which was characterized by a $t(8 ; 9)(q 12 ; p 22-23)$ with breakpoint at $8 q 12$. FISH analysis of this case with painting probes (data not shown) confirmed the translocation, being excluded the involvement of other(s) chromosome(s).

Case 3 displayed a more complex rearrangement of PLAG1. G-band analysis revealed what appeared to be a balanced translocation $\mathrm{t}(5 ; 8)(\mathrm{p} 13 ; \mathrm{q} 12-13)$, that was confirmed by FISH using painting probes for chromosome 5 and 8 (Figure 1a and b). However, when PLAG1 status was investigated, instead of finding the expected PLAG1 split with signals on both der(5) and der(8), two small signals from PLAG1 on der(8), and absence of signal on $\operatorname{der}(5)$ were verified, which indicates that a complex cytogenetic rearrangement had probably occurred (Figure 1c). The same pattern was clearly detected by CISH in paraffin sections (Figure 1d).

\section{Identification of Cell Types Carrying 8q12 Rearrangements by a Combined Genotypic/Phenotypic Analysis}

Immunocytochemical techniques to assess calponin and cytokeratin immunoreactivity were applied to

Table 2 Cytogenetic and in situ hybridization data from 20 salivary gland tumors with chromosome 8 deviations

\begin{tabular}{|c|c|c|c|c|}
\hline Case & Cytogenetic & FISH PLAG1 & CISH/No of signals from PLAG1 & CISH/No of signals from cen8 \\
\hline 1 & $\mathrm{t}(8 ; 12)$ & Not done & 1(26.9\%):2(50.5\%):3(20.2\%):4(2.4\%) split & $1(32.4 \%): 2(66.2 \%): 3(0.9 \%): 4(0.5 \%)$ \\
\hline 2 & $\mathrm{t}(8 ; 9)$ & Split & $\begin{array}{l}\text { 1(11.2\%):2(48.0\%):3(38.3\%):4(1.5\%):>4(1.0\%) } \\
\text { split }\end{array}$ & $1(28.2 \%): 2(70.5 \%): 3(1.3 \%)$ \\
\hline 3 & $t(5 ; 8)$ & Split & 1(19.4\%):2(24.8\%):3(55.3\%):4(0.5\%) split & $1(33.8 \%): 2(65.3 \%): 3(0.9 \%)$ \\
\hline 4 & $\mathrm{t}(8 ; 10)$ & Split & 1(24.0\%):2(44.7\%):3(30.3\%):4(1.0\%) split & $1(32.4 \%): 2(66.6 \%): 3(1.0 \%)$ \\
\hline 5 & $t(3 ; 8)$ & Split & No results & No results \\
\hline 6 & $\mathrm{t}(8 ; 15)$ & Split & 1(24.9\%):2(44.6\%):3(28.7\%):4(1.3\%):>4(0.5\%)split & $1(33.6 \%): 2(64.5 \%): 3(1.4 \%): 4(0.5 \%)$ \\
\hline 7 & $\mathrm{t}(3 ; 8 ; 9)$ & Split & 1(19.5\%):2(38.5\%):3(38.5\%):4(3.5\%) split & $1(30.0 \%): 2(69.0 \%): 3(1.0 \%)$ \\
\hline 8 & $t(3 ; 8)$ & Split & 1(17.4\%):2(63.7\%):3(17.4\%):4(1.5\%) split & $1(30.0 \%): 2(68.9 \%): 3(1.1 \%)$ \\
\hline 9 & $t(3 ; 8)$ & Not done & 1(26.5\%):2(43.0\%):3(29.5\%):4(1.0\%) split & $1(32.0 \%): 2(66.5 \%): 3(1.5 \%)$ \\
\hline 10 & $t(3 ; 8)$ & No split & 1(19.0\%):2(70.8\%):3(9.7\%):4(0.5\%) split & $1(32.2 \%): 2(67.3 \%): 3(0.5 \%)$ \\
\hline 11 & $t(3 ; 8)$ & No split & 1(21.5\%):2(61.5\%):3(14.0\%):4(3.0\%) split & $1(38.0 \%): 2(62.0 \%)$ \\
\hline 12 & $\mathrm{t}(8 ; 9)$ & No split & 1(25.3\%):2(69.7\%):3(3.5\%):4(1.5\%) no split & $1(37.5 \%): 2(62.5 \%)$ \\
\hline 13 & $t(3 ; 8)$ & Split & 1(9.6\%):2(46.9\%):3(41.5\%):4(2.0\%) split & $1(22.5 \%): 2(75.6 \%): 3(1.9 \%)$ \\
\hline 14 & $t(3 ; 8)$ & Split & 1(18.0\%):2(45.5\%):3(33.8\%):4(2.7\%) split & $1(30.5 \%): 2(67.5 \%): 3(2.0 \%)$ \\
\hline 15 & +8 & Trisomic & No results & No results \\
\hline 16 & $t(5 ; 8)$ & Split & No results & No results \\
\hline 17 & $\mathrm{t}(3.8)$ & Split & 1(11.4\%):2(50.0\%):3(34.1\%):4(4.5\%) split & 1(32.3\%):2(63.7\%):3(3.0\%):4(1.0\%) \\
\hline 18 & $\operatorname{der}(8 q 12)$ & Split & $\begin{array}{l}\text { 1(2.3\%):2(13.3\%):3(6.8\%):4(9.6\%):5(13.8\%): } \\
\text { 6(14.7\%):7(12.0\%):8(10.5\%):9(9.2\%):10(3.2\%):> } \\
\text { 10(4.6\%) split }\end{array}$ & $\begin{array}{l}\text { 1(7.2\%):2(19.0\%):3(18.4\%):4(16.2\%): } \\
5(19.8 \%): 6(16.2 \%): 7(3.15 \%)\end{array}$ \\
\hline 19 & +8 & Trisomic & No results & $\begin{array}{l}\text { 1(18.8\%):2(47.6\%):3(21.6\%):4(12.0\%) } \\
\text { Trisomic }\end{array}$ \\
\hline 20 & $\operatorname{ins}(3 ; 8)$ & Split & No results & No results \\
\hline
\end{tabular}


a

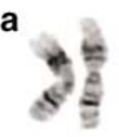

1

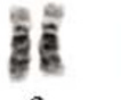

6

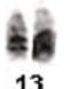

13

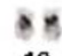

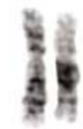

2

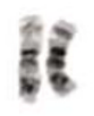

3

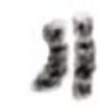

4

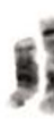

5
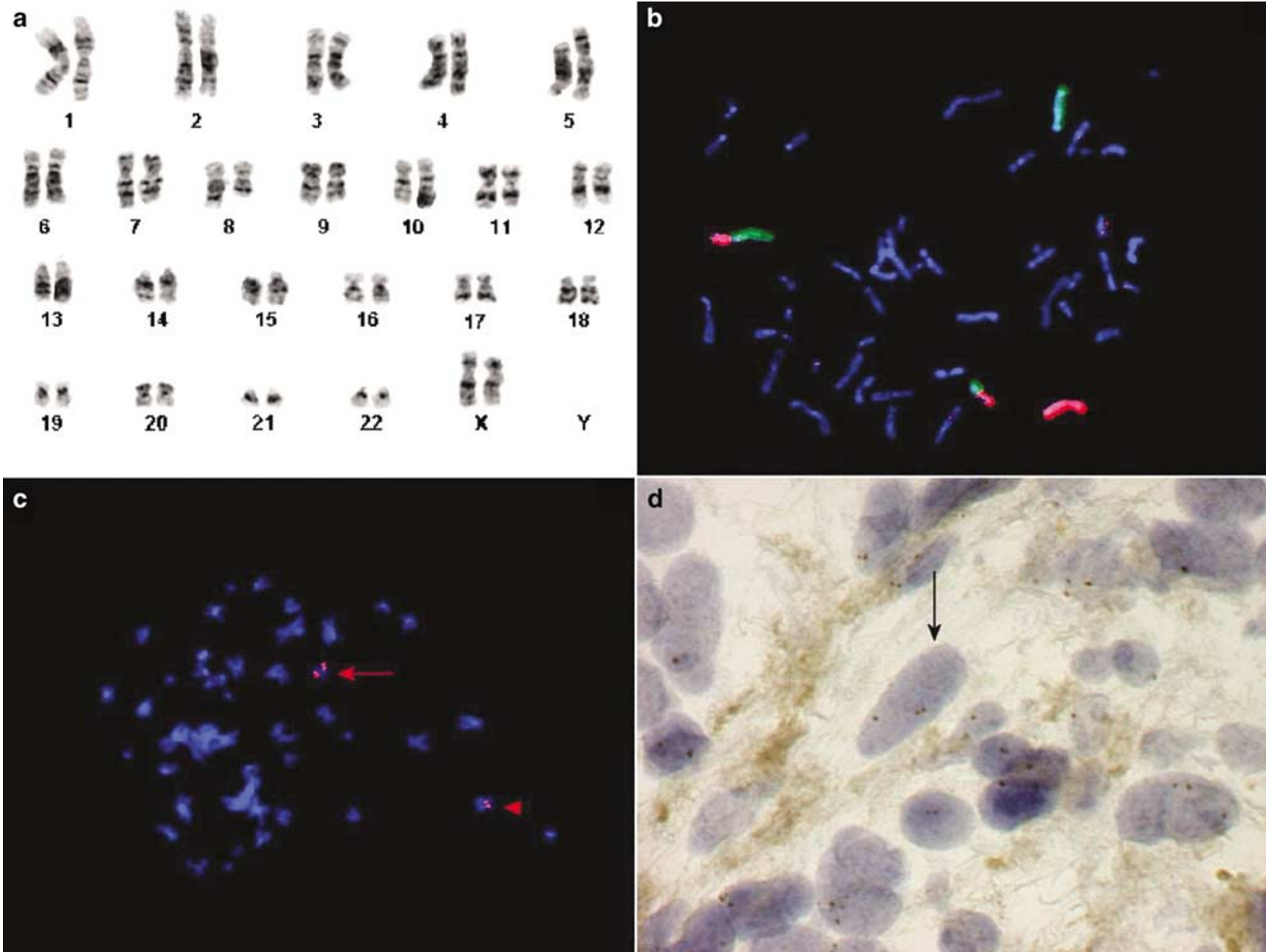

Figure 1 G-band and in situ hybridization analysis of a pleomorphic adenoma (case 3) with a t(5;8)(p13;q12-13). (a) Representative karyotype of the case; (b) FISH analysis with painting probes for chromosome 5 (green) and chromosome 8 (red), confirming the translocation; (c) FISH analysis with PLAG1 probe (red) with signal on normal chromosome 8 (arrow head) and with two small signals on the der(8) (arrow); (d) CISH analysis on a paraffin section, with PLAG1 probe; there are two adjacent brown spots, and a third spot confirming FISH observations.

investigate myoepithelial and epithelial differentiation of tumor cells from pleomorphic adenoma cases 2, 3, 4 and carcinoma ex-pleomorphic adenoma case 17, all of them characterized by $8 \mathrm{q} 12$ translocations and PLAG1 rearrangement. In order to establish the genotype of the cell population, the same slides were processed for FISH analysis using the PLAG1 probe. In all cases, the PLAG1 gene was found rearranged in either calponin- or cytokeratin-positive cells demonstrating that the (cyto)genetic lesion was shared by both myoepithelial and epithelial cells. Figure 2(a, b) illustrates in case 4 PLAG1 rearrangement in both cytokeratin- and calponin-positive cells.

\section{Discussion}

Our study describes a sizeable series of salivary gland pleomorphic adenomas, having in common 8q12 deviations and PLAG1 involvement, assessed by in situ hybridization techniques. Both metaphase and interphase tumor cells were evaluated which represents a new methodological approach using archival, formalin-fixed paraffin-embedded tissue. Additionally, it provides information on carcinoma ex-pleomorphic adenoma, a rare neoplasm in which very scarce information about the PLAG1 status is available.

This homogeneous series includes 17 tumors (85\%), being 14 pleomorphic adenomas and three carcinomas ex-pleomorphic adenoma, all showing intragenic rearrangements of PLAG1. Two tumors $(10 \%)$ had chromosome 8 trisomy without molecular cytogenetic evidence of PLAG1 rearrangement. Only pleomorphic adenoma case 12 , which is characterized by a $\mathrm{t}(8 ; 9)(\mathrm{q} 12 ; \mathrm{p} 22-23)$, with breakpoint at 8q12 lacked PLAG1 involvement. FISH analysis of this case performed with painting probes confirmed the translocation and excluded the involvement of other chromosome(s). In situ hybridization analysis performed either in metaphase or interphase cells revealed only two signals/copies of PLAG1 which indicates that no disruption of PLAG1 gene had occurred. In a recent study, Röijer et $a l^{28}$ 

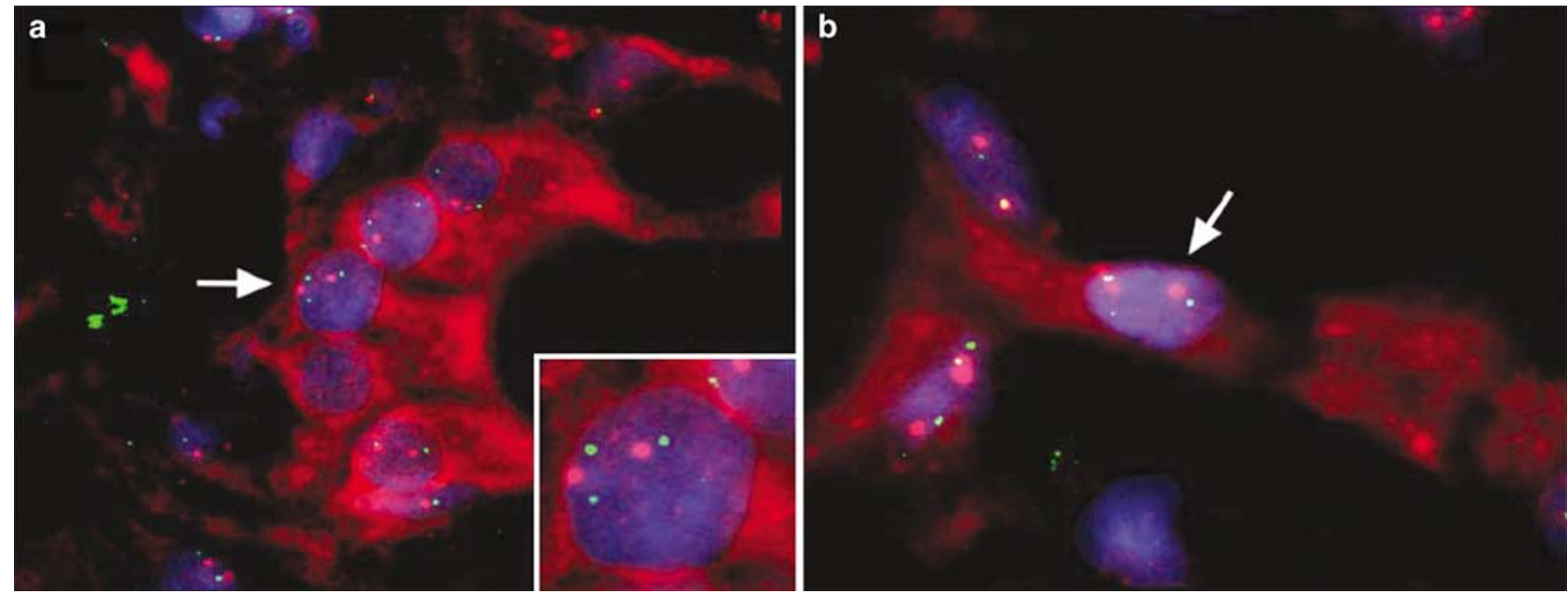

Figure 2 Combined immunocytochemistry and FISH analysis of a pleomorphic adenoma (case 4) with rearrangement of PLAG1 gene. (a) Cytokeratin (CK8-18)-positive cell (white arrow) showing the rearranged PLAG1 gene: three green spots can be observed corresponding one to the normal PLAG1 gene and two to the rearranged PLAG1 gene. Two red spots corresponding to two centromeres of chromosome 8 are present. (b) Calponin-positive cell (white arrow) also showing the rearrangement of PLAG1 gene (green).

described three pleomorphic adenoma cases with 8q12-13 rearrangements also without PLAG1 alteration. Further characterization of these cases will potentially shed light into the mechanisms behind these rearrangements.

PLAG1 involvement has been mainly reported in pleomorphic adenoma cases associated with $8 \mathrm{q} 12$ deviations, but it has also been shown to be activated in cases of pleomorphic adenoma either with normal karyotypes or with 12q13-15 abnormalities. ${ }^{710-12}$ In contrast to benign neoplasm, rearrangement of PLAG1 was only observed in a limited number of malignant tumors, mainly cases of carcinoma ex-pleomorphic adenoma. ${ }^{10,13,14}$

In the present study, except for one case (\# 12), all pleomorphic adenomas with 8q12 deviations had an intragenic rearrangement of PLAG1, which confirms the high percentage of this genetic event in pleomorphic adenoma and confirms its central role in salivary gland tumorigenesis.

Carcinomas ex-pleomorphic adenoma are uncommon neoplasm representing about $12 \%$ of all malignant salivary gland tumors. ${ }^{29}$ By definition they occur in the context of a previous or synchronous pleomorphic adenoma and they usually pursue an aggressive course. ${ }^{29}$ Histologically, they are characterized by the presence of benign and malignant areas, the latter usually having features of highgrade adenocarcinoma. ${ }^{2}$ Previous cytogenetic and molecular studies revealed that carcinomas expleomorphic adenoma have recurrent rearrangements at $8 \mathrm{q} 12$ and 12q13-15, the same chromosome regions affected in pleomorphic adenoma, and they also show consistent alterations at $17 \mathrm{p}$ loci (see ElNaggar et $a l^{30}$ for review). Consequently, PLAG1 gene rearrangement is expected to occur in cases of carcinoma ex-pleomorphic adenoma with $8 \mathrm{q} 12$ deviations. In this study, we found that the three 8q12 rearranged carcinoma ex-pleomorphic adenoma cases showed PLAG1 rearrangement which corroborates the involvement of this gene in tumor development.

The trisomy 8 is known to be the most frequent numerical deviation found in salivary gland tumors, being present in benign and malignant tumors. ${ }^{31} \mathrm{In}$ the present series, gain of chromosome 8 was the sole karyotypic aberration found in one case of pleomorphic adenoma and in one case of carcinoma ex-pleomorphic adenoma. The FISH analysis performed demonstrated that PLAG1 region was not structurally affected, since the two tumors had only one copy number gain of the gene. The mechanisms associated with gain of chromosomes are still unclear; the most plausible explanation is that gene dosage alterations predispose to tumor proliferation. A novel oncogenic mechanism involving PLAG1 copy number gain was described in the study of a series of lipoblastomas that presented polisomy for chromosome 8 without PLAG1 rearrangement. ${ }^{32}$ In this series, it was demonstrated that the $8 \mathrm{q} 12$ chromosomal rearrangements result in upregulated expression of PLAG1 transcription factor. It was hypothesized that, in polisomy 8/nonrearraged PLAG1 cases, PLAG1 could be transcriptionally upregulated, through a mechanism similar to the one verified in lymphoid neoplasms, such as Burkitt's lymphoma, in which point mutations in the promoter-region of $M Y C$ oncogene were detected in fusion gene-negative cases (see Gisselsson et $a l^{32}$ for review). Whether or not an analogous mechanism is present in salivary gland benign and malignant mixed tumors it remains to be elucidated.

One of the aims of our study was to compare the utility of in situ hybridization techniques applied to metaphase and interphase tumor cells using archived paraffin-embedded tissue and a specific-gene 
probe for the detection of gene rearrangements. Karyotyping mandates the establishment of a cell culture in vitro using a fresh sample of the primary tumor. In contrast, the in situ hybridization technique performed on paraffin sections, makes it possible to evaluate the in situ genetic alterations, in uncultured cells, avoiding in vitro manipulation and the need for fresh tissue. We found a fairly good agreement between the two techniques which allow to recommend their use in future studies. The in situ hybridization analysis of paraffin sections was shown to be a very sensitive technique as demonstrated in case 3 . Karyotypically, this case suggested the existence of a simple translocation between chromosomes 5 and 8 in the form of $t(5 ; 8)(p 13 ; q 12)$, an observation also confirmed by FISH with painting probes for both chromosomes. However, when PLAG1 status was evaluated by FISH in metaphase cells, two small spots from PLAG1 on $\operatorname{der}(8)$ were observed but none on der(5), prompting to consider that a more complex rearrangement occurred, such an inversion on chromosome 8 , which initially splits the PLAG1 locus, along with a translocation with chromosome 5. A similar phenomenon was also observed in pulmonary hamartomas of the lung, where hidden chromosomal inversions occurring together with simple translocations were also disclosed by FISH analysis. ${ }^{33} \mathrm{CISH}$ analysis on paraffin sections of this case revealed the same pattern, demonstrating that the in situ hybridization analysis is a powerful tool to assess PLAG1 rearrangements on paraffin-embedded archival tissues.

The second question addressed by this study was the investigation of the role of PLAG1 in the tumorigenesis and differentiation of pleomorphic adenomas. These neoplasms are morphologically characterized by a biphasic pattern of differentiation illustrated by the coexistence of epithelial and mesenchymal areas. Controversy remains on whether pleomorphic adenoma arises from a single pluripotent cell or more then one 'stem cell' is involved in the mechanism of clonal tumor expansion. ${ }^{17}$ There is increasing evidence that epithelial and myoepithelial cell populations share phenotypical and genotypical characteristics supporting the 'modified myoepithelial cell model' for pleomorphic adenoma histogenesis. ${ }^{16,17}$

Identification of cell types carrying PLAG1 rearrangements could help to clarify this issue. This prompted us to perform a combined phenotypic/ genotypic analysis on pleomorphic adenoma and carcinoma ex-pleomorphic adenoma cases of this series characterized by $8 \mathrm{q} 12$ translocations and PLAG1 intragenic rearrangement. In all cases, we identified cells expressing myoepithelial and ductal epithelial features. The genotype of the cells was established using FISH techniques, for the localization of 8q12 abnormalities that was verified in both calponin- and keratin-positive cells, which points to accept that the cytogenetic lesion is shared by epithelial and myoepithelial cell lineages. Further evidence to this conclusion came from the study of Debiec-Richter et $a l^{18}$ in two cases of pleomorphic adenoma characterized by $8 \mathrm{q} 12$ translocations. In this study, they investigated, which cell types expressed PLAG1 protein and they demonstrated that all cells that were strongly immunoreactive for PLAG1 carried the specific chromosomal translocations, and that they phenotypically, were either epithelial or myoepithelial. Our results and these data reinforce, therefore, the theory that postulates that pleomorphic adenoma cells originate in a single cell, a putative pluripotent element capable of differentiation into a variety of somatic phenotypes, as the model proposed by Batsakis and El-Naggar. ${ }^{16}$

\section{Acknowledgements}

This work was supported by a grant from Núcleo Regional do Sul da Liga Portuguesa Contra o Cancro. We thank Mateus Crespo, HT for technical support with FISH immunohistochemistry.

\section{References}

1 Dardick I. Histogenesis and morphogenesis of salivary gland neoplasms. In: Ellis GL, Auclair PL, Gnepp DR (eds). Surgical Pathology of the Salivary Glands. WB Saunders: Philadelphia, 1991, pp 108-128.

2 Waldron CA. Mixed tumor (pleomorphic adenoma) and myoepitheliomas. In: Ellis GL, Auclain PL, Gnepp DR (eds). Surgical Pathology of the Salivary Glands. WB Saunders: Philadelphia, 1991, pp 165-186.

3 Bullerdiek J, Wobst G, Meyer-Bolte K, et al. Cytogenetic subtyping of 220 salivary gland pleomorphic adenomas: correlation to occurrence, histological subtype and in vitro cellular behavior. Cancer Genet Cytogenet 1993;65:27-31.

4 Mark J, Dahlenfors R, Wedell B. Impact of the in vitro technique used on the cytogenetic patterns in pleomorphic adenomas. Cancer Genet Cytogenet 1997;95: 9-15.

5 Martins C, Fonseca I, Félix A, et al. Benign salivary gland tumors: a cytogenetic study of 21 cases. J Surg Oncol 1995;60:232-237.

6 Sandros J, Stenman G, Mark J. Cytogenetic and molecular observations in human and experimental salivary gland tumors. Cancer Genet Cytogenet 1990; 44:153-167.

7 Kas K, Voz ML, Röijer E, et al. Promoter swapping between the genes for a novel zinc finger protein an $\beta$ catenin in pleomorphic adenomas with $\mathrm{t}(3 ; 8)(\mathrm{p} 21 ; \mathrm{q} 12)$ translocations. Nature Genet 1997;15:170-174.

8 Hensen K, Van Valckenborgh IC, Kas K, et al. The tumorigenic diversity of the three PLAG family members is associated with different DNA binding capacities. Cancer Res 2002;62:1510-1517.

$9 \mathrm{Voz}$ ML, Mathys J, Hensen K, et al. Microarray screening for target genes of the proto-oncogene PLAG1. Oncogene 2004;23:179-191.

10 Åström A-K, Voz ML, Röijer E, et al. Conserved mechanism of PLAG1 activation in salivary gland tumors with and without 8q12 abnormalities: identi- 
fication of SII as a new fusion pleomorphic adenomartner gene. Cancer Res 1999;59:918-923.

11 Voz ML, Astrom AK, Kas K, et al. The recurrent translocation $\mathrm{t}(5 ; 8)(\mathrm{p} 13 ; \mathrm{q} 12)$ in pleomorphic adenomas results in upregulation of PLAG1 gene expression under control of the LIFR promoter. Oncogene 1998;16:1409-1416.

12 Voz ML, Agten NS, Van de Ven W, et al. PLAG1, the main translocation target in pleomorphic adenoma of the salivary glands, is a positive regulator of IGF-II. Cancer Res 2000;60:106-113.

13 Jin C, Martins C, Jin Y, et al. Characterization of chromosome aberrations in salivary gland tumors by fluorescence in situ hybridization (FISH), including multicolor COBRA-FISH. Genes Chromosomes Cancer 2001;30:161-167.

14 Tsang YT, Chang YM, Lu X, et al. Amplification of MGC2177, PLAG1, PSMC6P, and LYN in a malignant mixed tumor of salivary gland detected by cDNA microarray with tyramide signal amplification. Cancer Genet Cytogenet 2004;152:124-128.

15 Batsakis JG, Regezi JA, Luna MA, et al. Histogenesis of salivary gland neoplasms: a postulate with prognostic implications. J Laryngol Otol 1989;103:939-944.

16 Batsakis JG, El-Naggar AK. Myoepithelium in salivary and mammary neoplasms is host-friendly. Adv Anat Pathol 1999;6:218-226.

17 Dardick I. Mounting evidence against current histogenetic concepts for salivary gland tumorigenesis. Eur J Morphol 1998;36:257-261.

18 Debiec-Rychter M, Van Valckenborgh I, Van den Broeck C, et al. Histologic localization of PLAG1 (Pleomorphic Adenoma Gene 1) in pleomorphic adenoma of the salivary gland: cytogenetic evidence of common origin of phenotipically diverse cells. Lab Invest 2001;81:1289-1297.

19 Lee P-S, Sabbath-Solitaire M, Redondo TC, et al. Molecular evidence that the stromal and epithelial cells in pleomorphic adenomas of salivary gland arise from the same origin: clonal analysis using the human androgen receptor gene (HUMARA) assay. Hum Pathol 2000;31:498-503.

20 Noguchi S, Aihara T, Yoshino K, et al. Demonstration of monoclonal origin of human parotid gland pleomorphic adenoma. Cancer 1996;77:431-435.

21 Jin Y, Mertens F, Jin C. Nonrandom chromosome abnormalities in short-term cultured primary squa- mous cell carcinomas of the head and neck. Cancer Res 1995;55:3204-3210.

22 ISCN In: Mitelman F (ed). An International System for Human Cytogenetic Nomenclature. Karger: Basel, 1995.

23 Rogalla P, Borda Z, Meyer-Bolte K, et al. Mapping and molecular characterization of five HMG1-related DNA sequences. Cytogenet Cell Genet 1998;83:124-129.

24 Höglund M, Johansson B, Pedersen-Bjergaard J, et al. Molecular characterization of $12 p$ abnormalities in hematologic malignancies: deletion of KIP1, rearrangement of TEL, and amplification of CCND2. Blood 1996;87:324-330.

25 Alers JC, Krijtenburg PJ, Vissers KJ, et al. Interphase in situ hybridization to disaggregated and intact tissue specimens of prostatic adenocarcinomas. Histochem Cell Biol 1995;104:479-486.

26 Poddighe $\mathrm{P}$, Moesker O, Smeets D, et al. Interphase cytogenetics of hematological cancer: comparison of classical karyotyping and in situ hybridization using a panel of eleven chromosome specific DNA probes. Cancer Res 1991;51:1959-1967.

27 Jenkins B, Quian J, Lee HK, et al. A molecular cytogenetic analysis of 7q31 in prostate cancer. Cancer Res 1998;58:759-766.

28 Röijer E, Kas K, Behrendt M, et al. Fluorescence in situ hybridization mapping of breakpoints in pleomorphic adenomas with 8q12-13 identifies a subgroup without PLAG1 involvement. Genes Chromosomes Cancer 1999;24:78-82.

29 Gnepp DR. Malignant mixed tumors of the salivary glands: a review. Pathol Annu 1993;28:279-328.

30 El-Naggar AK, Callender D, Coombes MM, et al. Molecular genetic alterations in carcinoma ex-pleomorphic adenoma: a putative progression model? Genes Chromosomes Cancer 2000;27:162-168.

31 Mitelman F, Johansson B, Mertens F. Mitelman database of chromosome aberrations in cancer. http:// cgap.nci.nih.gov/Chromosomes/Mitelman 2004.

32 Gisselsson D, Hibbard MK, Dal CP, et al. PLAG1 alterations in lipoblastoma: involvement in varied mesenchymal cell types and evidence for alternative oncogenic mechanisms. Am J Pathol 2001;159:955-962.

33 Kazmierczak B, Meyer-Bolte K, Tran KH, et al. A high frequency of tumors with rearrangements of genes of the HMGI(Y) family in a series of 191 pulmonary chondroid hamartomas. Genes Chromosomes Cancer 1999;26:125-133. 